\title{
Pensar el 2001, interpelar a las subjetividades de la crisis. Entrevista a Diego Stulwark
}

\author{
Pondering 2001, Questioning the Crisis' Subjectivities. Interview with Diego \\ Sztulwark
}
Pensar o ano 2001, interpelar as subjetividades da crise. Entrevista com Diego Sztulwark

\author{
(iD) Ramiro Manduca \\ ramiromanduca@gmail.com \\ Instituto de Investigaciones Gino Germani (IIGG). \\ Universidad de Buenos Aires (UBA), Argentina \\ Maximiliano de la Puente \\ maxidelapuente@gmail.com \\ CONICET, Argentina \\ Instituto de Investigaciones Gino Germani (IIGG). \\ Universidad de Buenos Aires (UBA), Argentina \\ Universidad Nacional de las Artes (UNA), Argentina
}

Cita sugerida: Manduca, R. y de la Puente, M. (2021). Pensar el 2001, interpelar a las subjetividades de la crisis. Entrevista a Diego Sztulwark. Aletheia, 12(23), e107. https://doi.org/10.24215/18533701e107

\section{INTRODUCCIÓN}

El protagonista de esta entrevista, Diego Sztulwark, es un politólogo cuyo derrotero ha sido esquivo a los claustros académicos. Su quehacer profesional ha jerarquizado el pensar y el hacer con otres. Los emprendimientos que empuja revisten ese carácter dialógico: medios alternativos como el portal Lobo Suelto, editoriales independientes como Tinta Limón, los diversos grupos de lectura sobre los más variados tópicos que coordina año a año. Un rasgo que también se traslada a su obra en un "pensar piojoso", como él mismo 
recuerda que le señaló Ignacio Lewkowicz, en el que introduce autores y autoras construyendo textualidades corales desde las que emergen reflexiones de enorme singularidad. Ese quehacer intelectual encontró en el Colectivo Situaciones un laboratorio inigualable cuyo momento de irrupción está indisociablemente ligado al 2001. Esa experiencia, forjada desde un espacio multidisciplinar y en un vínculo estrecho con diversos movimientos sociales, dio forma a la práctica de la "investigación militante". Un modo de construir conocimiento en el que se apela a la abolición de jerarquías y donde las categorías son forjadas a partir del intercambio con los mismos sujetos que protagonizan un momento histórico. Un quehacer investigativo que reactualiza las metodologías para una ciencia social "desde abajo".

Ese acervo intelectual y vital subyace también en el último libro de Sztulwark, La ofensiva sensible. Neoliberalismo, populismo y el reverso de lo político (Caja Negra, 2018) sobre el que se centra esta entrevista. En diálogo con el dossier, nos pareció importante incluir esta conversación que toma como puntapié dicho libro porque allí el autor brinda un balance, desde la filosofía política, de la etapa que se abrió con la rebelión del 2001. Un libro que además tiene en sus trazos las marcas de una coyuntura específica, las del gobierno de Cambiemos y más específicamente, las del comienzo de su crisis. En el intenso intercambio que resultó ser esta entrevista, el 2001 aparece como la condensación de tiempos históricos, pretéritos y posteriores a ese año uno del siglo XXI. Allí se condensan las militancias de los '90 y los balances de los '70, pero también hacia ese momento se dirigen las miradas de una generación que hoy protagoniza los debates en la arena pública. Las siguientes páginas llevarán entonces a un recorrido que se aparta de toda linealidad, y al que por sus tópicos decidimos dividir en dos subtítulos: "Subjetividades de la crisis" y "Citas generacionales".

\section{Primera PARTE: SUBJETIVIDADES DE LA CRISIS}

Ramiro Manduca: El 2001 empieza a tomar un cariz histórico, se corre de lo estrictamente o inmediatamente político y entonces lo que aparece respecto a esto, y poniéndolo en relación con La ofensiva sensible, es la existencia de dos posibles memorias en disputa: ‘el 2001 debe ser leído como una crisis o como una rebelión? Es decir, se debe poner el acento en el carácter de la crisis o de la rebelión. Vos, claramente, cuando ubicas el punto cero de La ofensiva sensible, lo ubicas en el 2001 y lo ubicas como crisis. No aparece, al menos en ese comienzo, la lógica de la revuelta o la rebelión, es decir, tu decisión es pensar el 2001 desde la crisis y desde la productividad de la crisis. Me parece interesante, si bien lo desarrollás en el libro, poder conversar un poco sobre esa elección conceptual.

Diego Sztulwark: Siempre creí que el desafío de pensar el 2001 marchaba en la dirección contraria: no tanto la de distinguir y aplicar categorías (como "crisis" o "rebelión”) sino más bien en la de poner en cuestión el juego clásico de las categorías, así como la idea misma de una "aplicación” de esas categorías universales a una realidad particular. Al contrario, lo que hemos intentado nosotros, creo, fue pensar al mismo tiempo el funcionamiento de este tipo de rebelión tan particular que resulta inconcebible por fuera de la crisis, así como el funcionamiento de este tipo de crisis tan particular que tiende a adoptar la dinámica de una rebelión. Agrego que esta relación de implicación mutua entre crisis y rebelión alcanza también a los modos de pensar, que también entran en crisis, y son tomadas por un tipo de insubordinación que ya no permite el juego categorial de la "aplicación". Quiero decir que lo propio de la crisis de 2001 es comunicar su impureza a las categorías y a los modos de conocer.

Lo primero a decirles, para continuar, es que estas cuestiones las pensábamos en aquellos años al interior de un pequeño dispositivo militante, llamado Colectivo Situaciones. Y que el tipo de pensamiento que ejercitábamos formaba parte de una práctica específica, la "investigación militante", que es una manera de conectar íntimamente conocimiento a organización política. Y quizás valga la pena, entonces, decir unas palabras al respecto, contar una breve historia. Veníamos de una práctica de militancia universitaria, de las organizaciones estudiantiles independientes de los años 90. Habíamos formado a inicios de la década una agrupación llamada El Mate, en la Facultad de Ciencias Sociales de la UBA. Como parte de esa experiencia 
habíamos convocado, en el año '97, a las Cátedras Libres Che Guevara, a trienta años de su asesinato en Bolivia. El clima que se respiraba entonces era la previa al estallido, dentro de una crisis imparable. A veces se presenta al 2001 como una convulsión espontánea, otras como una manipulación conspirativa. Pero lo que nosotros vivíamos, al contrario, era una intensa actividad preparatoria, un tejido acelerado de agrupamientos de toda clase (no sólo universitarios, desde ya). Por aquellos años desde las Cátedras del Che funcionábamos en cierta coordinación con el Encuentro de Organizaciones Sociales, con organizaciones de Derechos Humanos, con la CTA de entonces, y más tarde con el naciente movimiento piquetero. Hubo muchísima producción pre 2001. Sobre esta dimensión de un tejido previo recae la siguiente paradoja: siendo la dimensión clave para comprender cómo se intersectan crisis y rebelión, es la dimensión menos destacada en las narraciones que circulan en el discurso periodístico y político. Por aquellos años -luego de la experiencias de las Cátedras Libres- nos organizamos como Colectivo Situaciones, con la tarea de salir de la universidad y volcarnos a la práctica de investigación militante. Percibíamos la intensidad de los movimientos magmáticos de la crisis, movimientos tectónicos que elevaban considerablemente la temperatura, y fuimos entrando en contacto con el desarrollo de las organizaciones sociales -o "movimientos sociales", como se los llama- a medida que la coyuntura se volvía cada vez más irrespirable. Ya en los años 2000 y 2001 la presencia de los movimientos piqueteros domina los territorios de la crisis y presiona sobre los sectores medios. Durante el año 2001 se producen bloqueos de acceso a la ciudad, y se va formando un clima de enfrentamiento, difícil de decodificar para sectores intelectuales universitarios. Creo hay ahí algunas claves para detenerse. Por un lado, el desborde con respecto al peronismo. Por primera vez en décadas, el peronismo era desafiado por un popular que no le respondía. La disputa entre el peronismo duhaldista y muchas organizaciones piqueteras llegó a ser una de las dinámicas centrales en el conurbano bonaerense.

Por otra parte, si bien es cierto que lo central de la crisis fue este fenómeno de desborde social con respecto a los ordenamientos políticos (sintetizada en la consigna "qué se vayan todos, que no quede ni uno solo"), hubo también un desborde con respecto a la capacidad de los llamados intelectuales universitarios de aquel momento por comprender lo que sucedía en tiempo real. Aquel desborde de las frágiles murallas del orden fue protagonizado contra todo pronóstico por la porción menos valorada de la clase trabajadora -llamada "desocupada"-, aquella que precisamente por ser definida como "sin trabajo", era desestimada como actor político. Quiero decir: lo nuevo no era que hubiesen desocupados, evidentemente, sino el hecho que hayan sido justamente estas masas desposeídas de derechos, salario y sindicato las que mejor hayan sabido resolver la cuestión de la organización y del protagonismo popular. Esta centralidad de las luchas piqueteras rompió los esquemas de cierta sociología que era incapaz de aceptar la posibilidad de que los sujetos expulsados del trabajo asalariado fueran capaces de lograr la auto-organización y la constitución de una respuesta contundente, pero también de una historia de los contrapoderes en la Argentina, porque este nuevo protagonismo social -nuevo por su composición, por sus formas organizativas y por su capacidad de acción colectiva- llegó para quedarse, imponiendo su impronta plebeya y su amenaza de desborde en cada recurrencia de nuestras crisis periódicas.

Volvamos a la pregunta. Decía que nuestro intento fue el de pensar juntas la crisis y la rebelión a partir de una reflexión interna a la crisis misma que no se reducía al fenómeno de los piquetes, sino a las múltiples manifestaciones de esta crisis-rebelión, que se extendían sobre un vasto territorio como una especie de tapiz muy variado y bien entretejido en las que co-existían experiencias de lo más variadas, pero que empujaban todas a decir basta al estado de cosas. Pongo un ejemplo que no pertenece al mundo de las organizaciones piqueteras, y que es tan conocido como conmovedor: la multiplicación de los escraches a los genocidas de la última dictadura -no sólo militares, sino también jerarquías eclesiales, empresariales- por parte de la organización HIJOS que habían comenzado a organizarse ya unos años antes con la consigna maravillosa: "si no hay justicia, hay escrache". Y también ahí, me parece, hay algo a revisar en profundidad en torno al modo en que estas experiencias han sido desleídas -quizás también por efecto de distinciones categoriales demasiado rígidas- con el tiempo. Si por un lado, esas formas de lucha -me refiero ahora concretamente a los escrachesgozaron de una amplia repercusión y fueron un factor esencial de la posterior reapertura de los juicios por 
verdad y justicia, por otro el "escrache" ha sido masivamente estigmatizado como una práctica de tipo no democrática o directamente "fascista", malversando una verdad tan frágil como necesaria respecto del modo de determinar el valor de una forma de lucha que surge al interior de una cierta correlación de fuerzas. Quiero decir: es evidente que cuando el escrache es realizado por personas afectadas por un poder estatal represivo, o en contra de figuras del poder concentrado, tiene un sentido inverso al que adquiere cuando se escracha desde el poder (o las prácticas empresariales de desabastecimiento).

Por elemental que sea este razonamiento, ha tendido a diluirse en un nuevo tipo de politización que no se preocupa por conservar estos modos de valorización. Los escraches de aquellos años se extendían en redes vecinales, ponían en juego prácticas populares de investigación y planteaban una serie de interrogaciones muy serias sobre los dispositivos del terror y la impunidad desplegadas por el propio Estado. Al mismo tiempo, esos escraches permitían reconstruir una memoria sobre la persecución y aniquilación de las prácticas militantes, las masacres, las desapariciones, los exilios. En fin, los escraches fueron una parte fundamental de las luchas comenzadas en los años setenta por las Madres de Plaza de Mayo en torno a la ilegimitdad de cualquier poder que se prolongase sobre las bases del genocidio. Me detengo en los escraches, como antes en los piqueteros pero, como sabemos, las figuras de la crisis dan lugar a una multiplicidad muy significativa de experiencias (de la recuperación de fábricas por parte de trabajadorxs, a los nodos del club del trueque por nombrar otras dos muy recordadas) que por razones que quizás podamos hablar más tarde podrían ser llamadas "micro políticas" no en un sentido de referir a grupos pequeños, sino en el sentido mucho más relevante de que eran elaboraciones estratégicas locales de problemas enormes, que se abrían desde abajo y recorrían el entero campo social. Puedo dar otro ejemplo más ligado a la profunda conexión entre crisis y rebelión, a partir de la experiencia de investigación militante. Durante muchos años trabajamos con una escuela de la zona oeste del conurbano -la Comunidad Educativa Creciendo Juntos de Moreno-, donde se planteaba con toda claridad el problema de la pretendida inclusión de lxs pibxs en una cultura en crisis, el problema de la invitación a un cierto futuro supone, desde luego, algún tipo de creencia en una cierta idea de futuro que valga la pena, cosa que en la práctica estaba completamente estallado en el plano económico y material más inmediato, aunque también en el plano simbólico, institucional y de horizontes. No eran -no son hoy- temas pequeños o menores sino cuestiones que nos atraviesan de un modo evidente. Nos interesaba identificar este tipo de cuestiones de un modo preciso, crear un lenguaje específico para dar cuenta de estas cuestiones desde las prácticas, como parte de las capacidades de las organizaciones populares (de un piquete a una escuela) para tratar los problemas de la propia existencia. La idea era que la investigación militante podía trabajar cuestiones importantes en situaciones concretas, allí donde estos asuntos se pueden tocar, indagar, donde es posible inventar procedimientos, generar redes concretas. Y, en ese sentido, por investigación militante entendíamos también la tentativa de poner a circular ciertas producciones que surgían del trabajo en taller armado redes propias.

Entonces, lo mínimo que puedo decir es que las páginas de La ofensiva sensible sobre 2001 están escritas en diálogo con antiguos pensamientos colectivos. No cabe decir “pensé el 2001 ”. No hay ahí una primera persona del singular, sino otra cosa. Un "pensamos 2001", que surge del dispositivo militante, en el cual yo estaba inscripto activamente en una trama más amplia: un colectivo, pero, además, un colectivo metido en ciertas redes aún más extensas. Este modo colectivo de actuar, de pensar, de enunciar es una marca fundamental para comprender una cierta reflexión en interioridad, en aquellos años. Si dos décadas después escribo sobre las "subjetividades de la crisis", estoy retomando una línea que no cabe reducir al tan cartesiano "yo pienso". Y eso puede rastrearse en la poca importancia de los nombres propios en las publicaciones de aquellos tiempos. ¡Vivíamos publicando! Al comienzo unos cuadernos y unos libros que preparábamos con un sello editorial que se llamaba "De mano en mano" (que traíamos de la época de la agrupación El Mate), luego creamos una verdadera editorial: Tinta Limón Ediciones. El primer panfleto que escribimos durante las jornadas de diciembre de 2001 ya hablaba de una "insurrección de nuevo tipo", cosa que desarrollamos en un libro llamado "19 y 20, apuntes para un nuevo protagonismo social”, que salió en marzo de 2002 (¡a toda velocidad!). 
En todos esos textos el "Nosotrxs" es reticular, impreciso, proliferante, dinámico. Digo: me parece que esa dimensión colectiva también respondía a un estado de crisis y rebelión en las vidas individuales.

Con respecto a las precisiones más puntuales sobre qué entender por crisis y rebelión, que es en el fondo una pregunta sobre las razones por las que empleamos conceptos como "insurrección de nuevo tipo", o como "subjetividad de la crisis", se puede agregar algo más: buscábamos distinguir una cierta novedad con respecto a la clásica "situación revolucionaria" -de la crisis al doble poder- que describía Lenin y sostiene una parte de la izquierda. No nos conformaba del todo el esquema según el cual de la crisis al doble poder las cosas se resolverían por medio lineal y veloz, a caballo de una vanguardia política capaz de aprovechar una crisis orgánica -definida como aquella en la que las clases dominantes ya no pueden y los dominados no se dejan dominar- para convertirla en una revolución. Pensábamos la crisis de otra manera. Menos aferrados a la idea de grupo de vanguardia (que además no existía empíricamente) y de la toma revolucionaria del poder (que tampoco estaba planteada). Tratábamos más bien de comprender esa coyuntura de revuelta en la que la dinámica colectiva hacía fracasar los intentos de las clases dominantes de disciplinar al conjunto social para aumentar la tasa de explotación y mantener la estabilidad política en condiciones inaceptables para grandes mayorías populares sin que madure algo así como un proyecto popular alternativo. En esas condiciones, se trataba, para nosotrxs, según creo, de actuar ligados a esa resistencia, cuya eficacia consistía en su capacidad de arruinar en lo inmediato aquellos planes de las élites. Esa rebelión tenía algo de inesperado. Una intensidad más o menos desconocida. Las organizaciones y colectivos que se dispusieron a participar en esa interioridad vieron muy claro desde el vamos que se trataba, ante todo, de decir "No". A sabiendas que decir "no" era agudizar -o generalizar- la crisis. Eso fue lo que ocurrió. El "no al ajuste" que proponía el desgastado bloque de clases dominantes eclosionó en diciembre del 2001. 19 y 20 de diciembre son incomprensibles por fuera de la maduración de esta capacidad formidable de sostener el ¡no!. Cuando usamos la expresión "subjetividades de la crisis" nos referimos, precisamente, a una serie de prácticas de subsistencia, de existencia, y de organización que permitieron sostener material y subjetivamente esa fuerza del no. Lo realmente importante de aquella experiencia fue que las organizaciones fueron capaces de apropiarse de la dinámica de la crisis. Aprendieron a habitar la crisis, a disputar la crisis que nos imponían desde arriba, a llevarla a extremos ingobernables. Haciendo emerger en ese punto nuevas tácticas que abarcaron modos de producción, de intercambio, de justicia, de lenguajes, de ocupar los territorios: toda una indisciplina que tornó posible una enorme impugnación a las élites políticas. Si se puede hablar de aquellos años como de un "poder destituyente", es en el sentido positivo de bloquear la capacidad de las élites de apropiarse de la dinámica de la crisis para sus fines. Apropiación que, como sabemos bien, consiste en usarla como amenaza para lograr bajar salarios, disciplinar a la población, aterrorizar. Esa novedad vino acompañada, por supuesto, por una cierta pérdida del miedo, que también quiere decir que diciembre de 2001 preparó el camino para el fin de la postdictadura. Cosa que se hizo muy evidente cuando el entonces presidente Fernando De la Rúa declaró el 19 de diciembre el "estado de sitio", y la gente le sugirió muy callejeramente que más bien se lo "meta en el culo". Algo había cambiado.

Entonces, digamos, "insurrección de nuevo tipo" y "subjetividad de la crisis", son nociones propias de una rebelión, pero de una rebelión que -como todas las ocurridas en la región en esos años- no se adecúa a esquemas, y más bien nos libera de la penosa tradición intelectual que consiste en "aplicar" categorías a la realidad.

Dicho esto, me parece que, para hablar de La ofensiva sensible, del modo en que aparece ahí la noción de "subjetividades de la crisis", habría que hacer al menos dos consideraciones. Una, que interesa menos, tiene que ver con entender qué tipo de transformaciones operaron en el pasaje de una enunciación colectiva a la individual -en mi caso, La ofensiva es el primer libro que firmo con mi nombre, sin forma colectiva o asociaday otra mucho más relevante, que tiene que ver con cómo se delimitan posiciones con ciertas izquierdas con los que, a pesar de compartir parcialmente referencias históricas y bibliográficas, tenemos diferencias fuertes de sensibilidad, de estilo, de modos de lectura y hasta de posiciones éticas. Entonces, cuando digo (o decimos) 
“crisis desde abajo" -sea en 2001, o desde la perspectiva de 2019 o en 2021-, de lo que estamos hablando es, ante todo, de un fenómeno de desacato, de desestabilización, de sustracción y desborde, de una cierta reacción ante la crisis, sí, pero de una reacción que contribuye a radicalizarla desde dentro.

Quizás podríamos hablar de una reacción-producción, con esa mutua implicación, que no es la del sujeto revolucionario convencional, que quizás no sea más que una ficción que satisface categorías y esquemas aprendidos en las escuelas de formación política de los partidos de izquierda. Entonces, sí, se trata de afirmar respecto del 2001 un tipo de comprensión apto para seguir derivas de politizaciones que no responden a molde alguno, sino más bien que actúan como parte de fenómenos que sólo pueden ser desplegados y comprendidos si se avanza en y con ellos, descubriendo su dirección y sus intensidades en el camino.

Maximiliano de la Puente: Recién nombraste, justamente, como una de las prácticas de aquel momento, por ejemplo, los escraches de HIJOS. En La ofensiva sensible, definís a este tipo de prácticas, ya sea los escraches u otras como los piquetes o las fábricas recuperadas, las asambleas, los clubes de trueque, etcétera, como prefiguraciones de formas post-estatales. Y allí me interesa preguntarte cómo lo percibís hoy. O sea, si desde tu perspectiva hoy se pueden percibir otras o nuevas formas post-estatales que se configurarían, justamente, como alternativas al orden de las cosas, en el marco de esta nueva crisis. Llegamos a 20 años del 2001 afrontando una crisis muy severa, de otro tipo, pero muy severa también. Entonces, cómo verías esa idea de la prefiguración de formas post-estatales hoy en día, si eso es una posibilidad o no y, en ese caso, en dónde estaría esa posibilidad, en qué prácticas lo podrías ver.

Diego Sztulwark: Me parece que en torno a la noción de lo "postestatal" hay como dos fuentes. Una, vinculada a las cosas que se pensaban esos años en torno a Ignacio Lewkowicz y que luego continúa hasta donde sé sobre todo Pablo Hupert -pienso sobre todo en su libro El Estado postnacional, más allá de kirchnerismo y antikirchnerismo (editorial Pie de los hechos, Buenos Aires, 2011)-y otra fuente que viene del universo de las experiencias y discusiones de la autonomía obrera italiana, que nos llegan sobre todo a partir de la figura de Toni Negri, pero también a los textos importantísimo de Paolo Virno. Por el lado de Lewkowicz, la cuestión de lo post-estatal estaba íntimamente ligada al 2001 argentino. Hay muchos trabajos de Ignacio en esta dirección, pero sin dudas el más importante es Pensar sin Estado. La tesis de Ignacio ahí, es que la posición soberana del Estado -entendida como capacidad de dotar de sentido a los modos de habitar las institucionesse viene abajo por efecto de una serie de mutaciones de un capitalismo que intensifica la coordinación de sus operaciones a partir de dispositivos de mercado, presionando sobre los propios Estados para que devengan entes reguladores inmanentes de la nueva situación, entes meramente técnico-administrativo, y no ya meta institución capaz de proporcionar cohesión social y significación a los agentes institucionales. Él no escribió jamás que el Estado desaparecía como aparato, institución o realidad política. Lo que desaparecía para él era más bien esta capacidad de producir obediencia a priori, la metainstitución coordinadora de instituciones, donadora de sentido. Y es esa desaparición lo que había que saber escuchar en la consigna "que se vayan todos, que no quede ni uno solo". Desde su punto de vista, entonces, el 19 y 20 no era tanto un momento antiestatal, como una cierta toma de conciencia popular de una nueva consistencia de los lazos sociales, ya no funcionaba por la vía de un común sometimiento a una instancia reguladora soberana, sino por un sistema abierto y contingente conexiones sobre el suelo líquido del mercado. En el fondo, la tesis de Ignacio apuntaba a una mutación radical en el orden de las subjetividades (que ya no podrían ser estatales ni antiestatales, sino solo postestales). Lo que quedó pendiente de desarrollar en su planteo, me parece, es la cuestión del nuevo valor de la política en las nuevas condiciones postestatales. Me parece que la dirección que Ignacio quería seguir era doble: por un lado, le interesaba el tipo de subjetividad -en particular durante el primerísimo kirchnerismo- apto para constituir capacidades estatales postsoberanas -al respecto, la referencia ineludible es el libro Habitar el estado, de Mariana Cantarelli y Sebastián Abad-, pero quizás también, averiguar, de un modo más amplio, qué tipo de potencias políticas eran posibles una vez superada la escena de la disputa 
cerrada por el acceso al poder del Estado que él como historiador consideraba agotada luego de los años setentas. Pienso que este tipo de discusiones se cruzaban en direcciones múltiples con nuestros propios planteos de un contrapoder, que tenían otro tono, que abrevaban en imágenes de las luchas de los años setenta, o en las "máquinas de guerra" en Deleuze y Guattari, en un fuerte intento por pensar la lucha de clases en este nuevo contexto. Desde ya que podemos preguntarnos si la idea de una postestalidad se constata o no desde la perspectiva de estos veinte años. Mi balance es que el kirchnerismo aniquiló la tentativa de este tipo de narraciones sobre la post-estatalidad, pero que los principales límites del kirchnerismo se pueden explicar perfectamente bien a partir de muchas de las indicaciones de Lewkowicz sobre la narrativa de lo estatal. Creo que Ignacio fue el que más claramente percibió entre nosotros que 2001 era un punto de inflexión en dos direcciones precisas: que toda reconstrucción de lo estatal estaría fuertemente condicionada por profundas subordinaciones a dispositivos de mercado (acá hay una punta fuerte para entender las críticas al neoextractivismo), y que esa presencia del mercado tiene más potencia que el Estado para crear subjetividades.

Luego, está la otra fuente, que es toda una literatura vinculada a lo que podemos llamar el autonomismo, en donde podemos recordar la figura de John Holloway, ligada al marxismo abierto y al zapatismo, pero sobre todo -al menos en nuestro caso- al citado Toni Negri, que venía de publicar Imperio, junto con Michael Hardt, en una audaz apuesta de leer juntos a Marx junto con Deleuze y Guattari. Imperio ofrecía una síntesis militante formidable a los discursos más interesantes del sesentiocho europeo, comenzando por Foucault, y era capaz de reunir la experiencia del post-obrerismo italiano, con la poderosa lectura que Deleuze había hecho de la filosofía de Spinoza. El libro era en sí mismo la propuesta de un nuevo espacio imaginario para las militancias, en la que ya no se trataba de pensar, como en la teoría política clásica, en base a unos individuos posesivos que pactan el sometimiento común a un soberano legal y que organizan sus deseos en el fenómeno del fetichismo de la mercancía. ¿Qué nueva imagen nos llegaba con Imperio? En lugar de individuos posesivos, singularidades capaces de composiciones de potencias variables de lo común, y por tanto, capaces de crear un deseo no sumergido en el fetichismo y reglas de acción no fundadas en la obediencia sino en la libertad. Imperio ofrecía, por un lado, una explicación de los nuevos poderes globales y, por otro, una nueva imagen de la capacidad de constitución política desde las luchas como procesos multitudinarios de autovalorización enfrentados a la explotación capitalista. El cambio de pantalla era grande, liberaba la política de la premisa según la cual los sujetos vivían presos de la modulación mercantil del deseo, además de sometidos a la soberanía estatal, y permitía concebir el papel de las subjetividades en producción de la crisis, poniendo en juego sus propias afecciones, dando lugar a composiciones anómalas incluyendo, desde ya, las invenciones en el plano organizativo. Se trataba de un cambio en la materia misma de la que se ocupaba la política. Un cambio que permitía partir de la cuestión de las formas de vida, y por tanto de las formas de crear justicia, sobre las formas de pensar estrategias, que ya no acepta una idea burguesa del estado centro de mando incuestionable. Nuevamente, ya no se trataba de afirmar cualquier cosa sobre el estado, sino de afirmar modos de actuar, de pensar y de ser político, compatible con nuevas lecturas de Marx, que siempre criticó lo político entendido como ámbito jurídico separado -fetiche del estado- para captar la realidad en su dimensión extra jurídica, fundada en relaciones de producción (en las que se afinca la realidad del estado). Esta fuente autonomista, le daba un cierto tono a la post-estatalidad, como concepto creado desde las luchas. Si Negri nos hablaba del avance de las multitudes, su compañero Paolo Virno, en cambio, venía a recordarnos las “ambivalencias" de esas multitudes. Virno hizo una contribución teórica esencial al proponer lo postestatal como escenario de disputa de clases, en las que el capital tendía a imponer su poder a la fuerza de trabajo partir de un estado excepción restringido (y no ya desde el monopolio de la decisión política asegurada), y por el contrario, la fuerza de trabajo -la multitud- ensayaba formas de contrapoder cuestionando toda forma de obediencia a priori a la ley (estado de excepción total). La sutil reflexión de Virno era capaz de captar el hilo que comunicaba las "ambivalencias de la multitud" con la ambigüedad de las formas políticas. El horizonte de la autonomía obrera italiana permitía pensar la afirmación de unas subjetividades plurales (multiplicidad de luchas obreras, populares, feministas, de derechos humanos, etc) actuando como contra-tendencias en el 
tiempo capaces de imponer límites a los avances del capital y solo en ciertos momentos plantear la cuestión del gobierno.

Para llevar adelante este tipo de análisis, es preciso, como mínimo, tomar dos recaudos: poner a Argentina en contexto regional sudamericano y asumir el tipo de temporalidad compleja que quizás nos permita la perspectiva de al menos un par de décadas. De este modo es posible establecer conexiones significativas entre nuestro 2001 y lo que está sucediendo hace un tiempo ya en Chile. En esa perspectiva temporal, podríamos ubicar también la coyuntura reciente de Bolivia que es otro escenario privilegiado de producción de crisis y de subjetividad. Ahora, el intento de sostener una perspectiva crítica -notablemente viva durante los últimos años en algunos movimientos, como el feminista- no supone automáticamente algún tipo de optimismo histórico. Lo que se constata, en todo caso, es una recurrente capacidad de decir "no", de poner ciertos límites, de dar testimonios, de narrar con un lenguaje propio -por fuera de la canallada comunicacional- lo que nos pasa, y de sostener la tradición "inconformista" como la llamaba Benjamin. Entonces, esta cuestión de lo postestatal funcionaba y quizás pueda seguir funcionando a partir de esta doble fuente que acabamos de analizar: como modalidad de hacer institución a partir de la excepción (una forma más horizontal del mando y del control), pero también como horizonte que se plantea por sustracción y desborde respecto de los modos de reglar la vida a la que aspira esa misma institución.

\section{SEgUNDA PARTE: CITAS GENERACIONALES}

Ramiro Manduca: En La ofensiva... hay un diálogo generacional muy claro. En esas discusiones, intercambios, diálogos que establecés, por ejemplo, con Javier Trímboli y lo que plantea en su libro Sublunar, con Silvia Schwarzböck y su lectura de la posdictadura, también, obviamente con Mariano Pacheco, pero con quién aparece una discusión muy clara es con Damián Selci. Esta discusión gira en torno a las potencialidades y los límites de las dinámicas sociales no estructuradas. Entonces, la pregunta es: ¿Qué rol juegan a tu entender esas dinámicas sociales no estructuradas en la posibilidad de establecer formas de vida que superen los modos de vida anclados en las lógicas del mercado?

Diego Sztulwark: Lo que me pasó leyendo la Teoría de la militancia, de Damián Selci, es que de repente me encontré con una inesperada puesta en contemporaneidad de modos de pensar que yo admiraba en los textos de los años 70 pero que, sobre todo a partir de las Cátedras del Che, veía como ideas que tenían que ser continuadas por medios nuevos. La aparición del zapatismo en los 90, y luego con el 2001, me parecen señales muy fuertes de otro tipo de protagonismo, de otras exigencias para pensar lo político. El libro de Selci me parece muy inteligente tanto por el modo en que lee las filosofías del populismo -la insuficiencia de la contradicción pueblo-oligarquía que evidencia el voto a Macri del 2015-, como la del acontecimiento -que él desplaza del 2001 a Cristina, pero también por la claridad con la que reflexiona sobre su propia experiencia militante argumentando la centralidad de la organización de cuadros como clave fundamental de lo político. Pero me parece que esas lecturas combinadas con sus creencias en la verticalidad organizativa y en la connotación casi sagrada de nociones como "dirección", "estructura" o "línea” van en dirección opuesta al intento de pensar el tipo de protagonismo social realmente determinante en nuestra región durante estas últimas décadas. En todo caso, si algo permite situar buena parte de los libros que edita Cuarenta Ríos (donde se publican los libros de Silvia, Javier, de Damián y de Mariano, así como La ofensiva) en una discusión común, es la común reacción ante el triunfo electoral de Macri. Son libros que están puestos a dialogar sobre el ciclo que va del 2001 o del 2003 hasta el momento de la derrota política del kirchnerismo, intentos de pensar esa secuencia.

Lo que me parece central del libro de Selci, en todo caso, es su crítica a un primer período del pensamiento populista de asumir la noción de pueblo como concepto político pleno, opuesto a la oligarquía. Su teoría de la organización militante se justifica precisamente en el hecho que el pueblo no es, a fin de cuentas, un dato unitario dado, sino que vota -y se comporta- como un ente dividido. Esa división, el descubrimiento de 
que una parte del pueblo puede identificarse con Macri, digamos, con lo neoliberal, lo hace revisar ciertos supuestos -lo que llama la "inocencia" de aquel primer populismo-. Y de esa revisión surge su idea de que la política -para él política kirchnerista, cristinista- debe cuestionar toda noción idealizada del pueblo y dar lugar a una comprensión encuadrada de pueblo organizado o militante. Lo que supone, al menos para él, una estricta ética del compromiso, que sólo puede encarnar en una organización cuyo vértice, en última instancia, coincide con Cristina Fernández. El atractivo que tiene su planteo es que la figura del militante queda planteada como una figura de la responsabilidad, el militante, en contraste con el pueblo no organizado -hedonista, consumista, idiotizado en su mundo privado, demandante, antipolítico, "cualunque"- es ante todo un sujeto que se hace cargo del mundo. Y el modo de hacer coincidir esa posición ética con su propia militancia en La Cámpora es consecuente. A mí modo de ver, esa posición tiene el enorme problema de eludir una historia argentina muy digna y estimable, que me interesa mucho más, que es la de las organizaciones políticas que, sobre todo cuando pensamos del ' 77 para acá, han protagonizado los momentos democráticos más interesantes, las luchas más inspiradas y eficaces, y los modos más intensos de responsabilización por lo público como son, evidentemente, las luchas por los derechos humanos, las luchas de los movimientos piqueteros, momentos particularmente importantes del movimiento sindical -como la CTA de fines de los 90-, los movimientos juveniles anti-represivos, los movimientos feministas, los movimientos ambientalistas, o los movimientos campesinos indígenas. Todas organizaciones que responden a formas más libertarias de organización. Por supuesto que no se trata de caer en una oposición caricatural entre espontaneidad y organización. Sino, en todo caso, de mostrar que hay más de un modo de practicar y concebir las formas de organización, y las últimas décadas, las más valiosas, han sabido constituirse en una enorme apertura y porosidad a los grandes momentos de lucha social de masas. El propio kirchnerismo, por otra parte, debe una buena parte de su legitimidad a este tipo de luchas de las que estoy hablando. A mi juicio, sus grandes momentos fueron momentos de radicalidad en la apertura. Y por eso creo que una buena lectura del kirchnerismo -una capaz de no poner el acontecimiento en el líder, sino en poner al líder como lector del acontecimiento- confirma un poco este razonamiento que estoy proponiendo. Todo lo que el kirchnerismo tuvo de interesante lo encontró construido por organizaciones populares de lucha, de las que quizás el propio kirchnerismo se sienta, por su posición en el Estado, su síntesis, culminación o superación (del mismo modo en que sus límites más obvios surgen de su incapacidad de escuchar una pluralidad de luchas sociales como las socioambientales). Evidentemente, este tipo de lecturas dividen aguas. Porque al menos para mí es completamente insostenible concebir al kirchnerismo como supuesta síntesis, culminación o superación de esas luchas. Insostenible y peligrosísimo. No porque ignore o desestime la importancia de que el Estado asuma en ciertos momentos y al menos parcialmente aquellas narraciones. Sino porque justamente, estos elementos narrativos surgieron de derrotas sucesivas frente al Estado mismo. Me parece que es indispensable sostener a como dé lugar esa dimensión autónoma de las narraciones de un contrapoder que de ningún modo se integra en el Estado sin conflictos y de modo definitivo. No me parece que haya beneficios al pensar así la política argentina y sudamericana, que siguen dependiendo, en lo que tienen de dinámica democrática y popular, de la propia dinámica de todo tipo de movimientos no unificables en una institución centralizada. Parto de la idea de que en América Latina hay una tradición particular a considerar, y es que las luchas de clases se abren a partir de movimientos -y organizaciones- populares no organizados como partidos tradicionales. Entiendo que esto pueda verse como un límite, pero también habría que reconocer que ha sido parte de su eficacia. Y esa eficacia no siempre es visible en los llamados gobiernos progresistas o populistas. Entonces, la discusión quizás pueda plantearse entre dos imágenes del contrapoder: ¿el contrapoder es organización militante que apuntala al Estado progresista, o es formación de movimiento social con horizonte estratégico propio? $\mathrm{O}$ también: ¿el contrapoder tiende a "encarnar" -y uso esa palabra teológica con toda la intención- en un(a) líder y una organización, o en una multiplicidad de instituciones -líderes, procesos de toma de decisiones- de nuevo tipo? No formulo estas preguntas porque crea que las cosas se resuelvan de un lado o de otro, de modo definitivo, sino, al contrario, porque creo que los procesos se atraviesan formulando con la mayor claridad 
posible estas alternativas, abriendo cuestionamientos. Desde mi perspectiva, la cuestión pasa mucho menos por el arte de la "encarnación" y mucho más por los oficios de una inmanencia abierta, es decir, de formas de leer la cuestión de la organización política en función de dinámicas auto-instituyentes del campo social.

Maximiliano de la Puente: Hay varias cosas o, por lo menos, niveles que nos había interesado pensar o charlar con vos. Respecto a lo generacional, este aspecto en La ofensiva se presenta de la mano Benjamin, al traer el uso del concepto de historia y al hablar de la "cita secreta entre las generaciones pasadas y las actuales”. Entonces, aparece esto que vos mencionas recién respecto a cómo nuestra generación tiene que pensar no en términos de éxito, de victoria, sino más bien de atestiguar, la figura del testimonio, el testigo y también la figura de la negativa. Lo que te quería preguntar es, siguiendo con esta cuestión de lo generacional, cómo pensás, retomando a Benjamin, esa cita con las generaciones pasadas. Cómo fue en tu caso esa cita con las generaciones pasadas, pensando en 2001 y también la experiencia con la investigación militante que mencionabas al comienzo. Me remitiría, por ejemplo, a la de los '70. ¿Habría, entonces una conexión entre los ‘70 y el 2001 desde tu perspectiva, o no? ¿Cómo lo verías, en ese sentido, en términos más benjaminianos y pensándolo de esta manera, en términos generacionales?

Diego Sztulwark: En el momento en que comenzamos a conversar con la editorial Caja Negra sobre lo que luego sería La ofensiva sensible, estaba metido en la escritura de un libro de conversaciones con el periodista Horacio Verbitsky: Vida de perro. Balance de un pais intenso, del 55 a Macri (Siglo XXI, Bs-As, 2018). Esas conversaciones fueron importantes para mí, en la línea de un cierto estado de balance, de lectura, de pregunta de cómo se había llegado a la coyuntura política macrista. Se trataba para mí de plantear a Verbitsky una serie de cuestiones, y en algunos puntos también de confrontaciones, sobre el período 2001-2015, pero también de pensar un lapso histórico mucho más amplio y también de reflexionar sobre la cuestión de la investigación, asunto me acompañaba desde la época del Colectivo Situaciones. Me parece evidente, entonces, que había un fuerte componente generacional en estas conversaciones. Componente que para mí se cruza con el modo en que él se es kirchnerista y con mi modo de no serlo. Un día, hacia el final de nuestros encuentros, Horacio toma la iniciativa y me hace un planteo completamente inesperado: "bueno, ya me preguntaste todo lo que querías saber y yo te respondí a todas tus preguntas.

Ahora contame vos: ¿qué esperabas encontrar, y qué encontraste en esta conversación?”. Mi respuesta, que está por supuesto en el libro, fue algo así como: "yo quería responderme a una duda: ¿por qué si desde que comencé mi militancia y leía tus columnas dominicales en Página 12 como el principal insumo de comprensión de las coyunturas -me refiero sobre todo a los mapas que el perro fue haciendo de los militares carapintadas, de los grupos económicos, de las bandas judiciales, de las operaciones policiales, de la historia política de la iglesia- resulta que ahora venimos a divergir en la coyuntura por tu notorio entusiasmo con el kirchnerismo, que a mi al contrario, me deja siempre un sabor más o menos amargo? A esa duda me respondo ahora con una cita tuya: el kirchnerismo coincidió con tu agenda -en particular en torno a los juicios de los milicos, a la narración de la historia- y no solo vos con la suya, y en cambio de mi modo de leer la experiencia de 2001 surgían otras expectativas, sobre todo en lo relativo a la centralidad que debían tener aquellos movimientos populares en la toma de decisiones políticas".

Esta escena me parece que conecta con la pregunta que me haces sobre Benjamin y las generaciones. Por un lado, hay una divergencia de estimaciones - ¿para qué daba el 2001 ?- y por otro, de concepciones -el problema de la autonomía de la política, todo el fenómeno de la representación y la idea de democracia. Quiero decir que la idea de inclusión que trajo el kirchnerismo, en toda su complejidad, vino también con un elemento de subordinación -y de desaprovechamiento- de saberes populares: la reivindicación que se hizo desde el Estado de las militancias no fue nunca en el sentido de colocar a los movimientos populares de aquellos años en el centro de la toma de decisiones. Se confió más en una concepción de la reparación, y en la proposición de un tipo de inclusión en el mundo del trabajo que evidentemente no produce los niveles de igualación que el 
discurso de la inclusión pretendía. Creo que todo esto puede ser pensado en términos también generacionales, en el punto en que la imposición de un cierto modo de pensar, más propio de los años setenta, se impuso sobre percepciones que estaban forjándose en el 2001 sobre la estructura social argentina, sobre la importancia de crear otro tipo de instituciones, sobre lo que implica reconocer un nuevo tipo de protagonismo colectivo plural. En torno a todo eso hubo después de 2003 un enorme silencio, una zona muy difícil de afrontar abiertamente. Pero eso que no se pensó, y que a mí me queda como distancia y punto de desencuentro muy fuerte con el progresismo político actual, no deja de volver como contradicción y límite muy fuerte en la experiencia de gobierno actual. Recuerdo que llegamos a plantear este tipo de cuestiones en el último trabajo que armamos como Colectivo Situaciones, titulado Conversaciones en el impasse (2009). Creo que esa crítica política, a los modos de concebir las prácticas, y el habla política del progresismo no se ha desarrollado lo suficiente por una razón muy sencilla y muy clara: la presencia de un enemigo -uso esta palabra de un modo intencional, y quizás valga la pena luego decir algo sobre las formas no fascistas de concebir la enemistad- en un sentido común muy despiadado y cruel. Perdura ahí una escisión. Pensamos diferente, queremos cosas diferentes, pero muchas veces votamos lo mismo, o vamos a la misma plaza. Esa tensión acompañó todo el proceso de presentación de Vida de perro. Es la tensión propia en todo ese período de cómo se desarrolla un frente antineoliberal entre sectores que no tienen las mismas concepciones.

Mencionaban también los libros de Javier Trímboli y Mariano Pacheco. Con ambos comparto, sobre todo, las interpretaciones del 2001 y la discusión tan importante sobre lo que se juega en los años 2002 y 2003 . El libro de Javier pone el ojo ahí donde a Selci no le interesa mucho mirar. Ese lapso fundamental que va del "pueblo insurrección" a la voluntad de reparación del kirchnerismo. También Mariano pone mucha atención a esos pocos años claves, que son los de la masacre de la estación Avellaneda. Desde perspectivas distintas, los dos se preguntan qué pasó esos años. Me parece que Mariano ve ahí el cierre de un ciclo de luchas y Javier se centra en su propia experiencia de haber escuchado una convocatoria, un nuevo proyecto que lo toca y lo convence. Y sin embargo, cuando nos cuenta en qué consiste el sentido de esa experiencia -el kirchnerismo en el poder-habla de una manera clara sobre la ausencia de proyecto estratégico, del modo en que la izquierda ya no funciona como la fuerza del progreso -condición esa que sí le reconoce al neoliberalismo-, y en todo caso, de su voluntad por impedir que ese progreso neoliberal siga triunfando. Entonces, sea desde la idea de que el ciclo de luchas antineoliberales del 2001 traía una novedad -como piensa Mariano y que comparto-, o bien desde el reconocimiento de la ausencia de un proyecto alternativo fuerte -como creo que dice Javier-, lo generacional aparece en ambos casos como una confrontación con relación a la generación de los años setenta. Y hasta como una cierta incapacidad de afirmación propia frente a la experiencia tremenda de aquella generación. Ese sería, me parece a mí, el asunto benjaminiano (pensando en aquella cita de Bejamin que ustedes traen, y que está tan conectada con aquella idea suya según la que cada generación trae consigo un "débil poder mesiánico" que no debe derrochar). Y en eso me siento próximo a Mariano: creo que es el 2001 y no el kirchnerismo el que iluminaba "el débil poder mesiánico" de algo así como una nueva generación, en un sentido fuerte. Y cuando afirmo esto, estoy recordando el trayecto grupal que les conté antes, la experiencia de El Mate y de las Cátedras del Che, la experiencia que hicimos luego con el Colectivo Situaciones: todo ese recorrido estuvo signado por la búsqueda de la cita "perdida” con las generaciones pasadas. No imaginábamos la relación con la generación anterior como una continuidad lineal. Cuando en la época de la Cátedra del Che fuimos a buscar a lxs militantes de aquellos para escucharlos, jamás vimos en ellxs jefaturas políticas. Se trataba, más bien de asumir una conversación intensa con los restos de una experiencia y de una derrota, porque esos restos tenían cosas muy importantes que comunicarnos, faltaba y precisábamos una transmisión más fina de aquella aventura de tipo revolucionaria, necesitábamos saber más y más, pero para descubrir en la diferencia de contexto nuestro propio deseo, en una escena completamente nueva, que no podría codificarse en los mismo modos en que se hicieron en los ' 70.

Entonces, había ahí un trabajo para calibrar que podíamos tomar como continuidad y en donde habría que fijar las discontinuidades. En ese sentido nacía, sí, algo generacional quizás en torno al 2001. A fines 
de los '90 la pregunta que nos perseguía era: ¿cómo se continúa un proyecto revolucionario sobre nuevos términos que no son ya los de los '70?. No veíamos modo de hacer ese pasaje sin entrar en contacto con esos testimonios tan difíciles, tramados también por el horror de la dictadura. Entonces había que atravesar el discurso de los derechos humanos buscando conocer más de cerca cómo había sido aquella experiencia, conocer de cerca aquel dispositivo de subjetivación, que ya no podía ser el nuestro. Se trataba de hacer una operación de contacto y deslinde. Esto está presente en El Mate y está presente en el Colectivo Situaciones (las primeras publicaciones las sacamos con el Colectivo ponemos en las contratapas con una foto del "Che", algo irónico, con un habano): nunca dejamos de percibir la marca de la continuidad, incluso a nivel continental, con las luchas del pasado, como modo de identificación, pero desde una posición propia que nos obligaba a pensar de qué se trataba nuestro presente.

En ese sentido, sí creo que 2001 es el punto de máxima tensión irresuelta en el diálogo entre estas perspectivas. Y mi impresión es que lo que acabó imponiéndose es la cultura política que venía de los años setenta, solo que esa cultura política funciona hoy inevitablemente muy de otra manera, por fuera del horizonte revolucionario que le dio todo su sentido en su hora. Javier dice que la convocatoria del kirchnerismo a la militancia no se hace en nombre de la revolución, sino de la historia. Y a mí me parece que eso es cierto a condición de asumir que el sujeto de esa historia sigue teniendo el eje de gravedad en aquella generación. Mi sentimiento, al respecto, es que sin quererlo acabamos por derrochar algo de ese "débil poder mesiánico". Y esa debilidad nuestra se nota mucho en el discurso posterior del kirchnerismo militante.

Ramiro Manduca: Siguiendo un poco el hilo de pensamiento y también algunas de las reflexiones de $L a$ ofensiva..., las reflexiones en torno al periodo 1983-2001, y el tránsito durante esas décadas de la figura del ciudadano a la del consumidor, en vínculo a esto último que decís en torno al kirchnerismo, pareciera ser que hay algo que no se logra romper, sino que tiene rasgos de continuidad. Pongo un ejemplo muy claro, que además coincide con los años donde seguramente estabas trabajando en este libro, donde esto se ve claro y que además tuvo cierta relevancia para los sectores intelectuales y progresistas. Me refiero a lo que fue la cumbre de CLACSO, cuando interviene Cristina, con un mensaje de ferviente oposición al macrismo, anclando su crítica a lo restringido del acceso al consumo de los sectores populares, por lo tanto, acentuando la condición de consumidores y no de ciudadanos...

Diego Sztulwark: Exacto.

Ramiro Manduca: Eran al mismo tiempo momentos de una ofensiva fuerte del macrismo y en algún punto que, de la principal figura política opositora, apareciera la apelación a la figura del consumidor dejaba un sabor amargo. Tendía a anular una imaginación política capaz de pensar otras ciudadanías.

Diego Sztulwark: Sí, en ese discurso, Cristina además dijo que los "movimientos sociales" que existen hoy, eran antes "organizaciones sociales". Intuyo que algunos movimientos sociales suscriben este tipo de descripciones, aunque no estoy tan seguro de que las organizaciones de aquellos años hubieran hablado del mismo modo. Es un discurso que desplaza los términos y tiende a borrar un protagonismo previo a la llegada del kirchnerismo al poder (un protagonismo que de un modo indirecto hizo mucho para que luego de 2003 el kirchnerismo tuviera un espacio posible, antes inimaginable). Cristina piensa así. En su libro, Sinceramente, relata aquellos años con una agilidad asombrosa. Esa distancia respecto a luchas que impugnaron al neoliberalismo de los '90 forma parte de un modo de leer y presentar las cosas según la cual lo colectivo solo adquiere valor visto desde arriba. Por fuera del relato estatal, las luchas serían dignas, si, pero prepolíticas. Con lo que deberíamos volver a mirar de cerca qué ocurrió en aquellos años que van del 2001 al kirchnerismo. Años de una transición que no se explican del todo sin prestar atención al asesinato de Kosteki y Santillán. La masacre de Avellaneda tiene tres efectos centrales: golpea en los movimientos populares, fuerza un llamado a elecciones, acelera la candidatura de Kirchner por parte del duhaldismo. La lucidez con que el kirchnerismo lee 2001 es inseparable del hecho de que esa lectura es hecha desde otro propósito y desde otro 
lugar. Y creo que ese otro lugar es el que podemos leer en aquella frase de Cristina. Aquel discurso fue una auténtica prefiguración de la realidad política que tenemos hoy. Si descontamos la pandemia, lo que Cristina planteaba en ese discurso era a la vez un balance del período nefasto 2015/2019 y las coordenadas del actual frente antimacrista en el poder, en la que la posposición de las demandas populares se adjudica por entero a la pandemia. Un gobierno que pide disculpas a la sociedad por el escándalo por las fotos del presidente en un brindis durante la cuarentena, y calla ante el violento desalojo de la ocupación de tierras de Guernica en manos del coronel Beni. Mi sensación es que el anti-macrismo que Cristina organizó conceptualmente en aquel discurso es tan necesario como insuficiente, aunque esto no pueda ser discutido abiertamente. Por lo que la necesidad de otro tipo de práctica colectiva tiende a perder contacto con la política convencional. Puede que me equivoque -es lo habitual-, pero a mí no me parece que el anti-macrismo alcance en este momento ni siquiera para salvarnos del macrismo. Y en todo caso me queda claro que no es desde ahí que podemos pensar el 2001. 